\title{
Structure Activity Relationship of Stable Dynorphin A-(2-13) Analogues Interacting at the Bradykinin-2 Receptor
}

\author{
Sara M. Hall ${ }^{1}$, Yeon Sun Lee ${ }^{1}$, Cyf Nadine Ramos Colón ${ }^{1}$, Frank Porreca², \\ Josephine Lai ${ }^{2}$, and Victor J Hruby ${ }^{1}$ \\ ${ }^{1}$ Department of Biochemistry and Chemistry; ${ }^{2}$ Department of Pharmacology, \\ University of Arizona, Tucson, AZ, 85721, USA
}

\section{Introduction}

Neuropathic pain effects 100 million Americans and imposes a significant public health problem. This type of pain results from the dysfunction of the central nervous system (CNS) or the peripheral nervous system (PNS) that can occur in the presence or absence of an initial injury. Some of the current treatments for neuropathic pain involve opioids, non-steroidal anti-inflammatory drugs (NSAIDS), and anticonvulsants, namely gabapentin and pregabalin [1]. Many of these treatments are highly efficacious for acute pain but are not very effective in neuropathic pain and have serious side effects caused by long-term administration. Treatment for this disease is difficult with conventional methods, partly because the mechanism of this disease is not well known.

One target for neuropathic pain treatment may be the blockade of Dynorphin A (Dyn A) (Figure 1). Dyn A, a proteolytic fragment derived from prodynorphin, has both inhibitory and excitatory effects in the spinal cord. The inhibitory effects of Dyn A are thought to act primarily through the opioid receptors, with the $N$-terminal tyrosine being essential for its high affinity and agonist activity. The opioid action of Dyn $\mathrm{A}$ is abolished by removing the $N$-terminal tyrosine, as the des-tyrosyl fragments of Dyn A do not bind to the opioid receptors $\left(\mathrm{IC}_{50}>10 \mu \mathrm{M}\right)$ [2]. However, these fragments are biologically active both in vitro and in vivo, and being neuroexcitatory and neurotoxic, suggest a non-opioid pathway. These des-tyrosyl fragments of Dyn A have been found to bind to the bradykinin 2 receptor (B2R) and cause an influx of calcium [3]. In a chronic pain model, Dyn A was found to be up-regulated and contributes to the maintenance of neuropathic pain $[3,4]$. Therefore, the development of B2R antagonists can be used to block the agonist actions of Dyn A which may lead to therapeutics for chronic pain.

$$
\begin{aligned}
& \text { dynorphin A: H-Tyr- } \mathrm{Gly}^{2}-\mathrm{Gly}^{3}-\mathrm{Phe}^{4}-\mathrm{Leu}^{5}-\mathrm{Arg}^{6}-\mathrm{Arg}^{7}-\mathrm{Ile}^{8}-\mathrm{Arg}^{9}-\mathrm{Pro}^{10} \text {-Lys }{ }^{11}-\mathrm{Leu}^{12} \text {-Lys }{ }^{13}-\text { Trp-Asp-Asn-Gln-OH } \\
& \checkmark \text { [des-Tyr }{ }^{1} \text {-Dyn A-(2-13) }
\end{aligned}
$$

Fig. 1. Structure of Dyn A. Box shows non-opioid fragment, Dyn A-(2-13).

\section{Results and Discussion}

\section{Structure Activity Relationship (SAR) of Dyn A Analogues at the B2R}

To explore novel therapeutics for neuropathic pain, a SAR study was performed with Dyn A analogues at the B2R in rat brain membranes. It was previously found that LYS1044 ([des-Arg $\left.{ }^{7}\right]$ Dyn A-(4-11), H-Phe ${ }^{4}$-Leu-Arg-Ile-Arg-Pro-Lys $\left.{ }^{11}-\mathrm{OH}\right)\left(\mathrm{IC}_{50}=150 \mathrm{nM}\right)$ is the shortest pharmacophore for binding at the B2R. This ligand was effective in vivo by blocking Dyn A-induced hyperalgesia in naïve animals and reversing thermal and tactile hypersensitivities in a dose-dependent manner in nerve injured animals [5]. Although this ligand was efficacious, it is composed of natural amino acids and therefore is susceptible to degradation by peptidases. In an effort to improve the peptide's stability, Dyn A analogues were designed and synthesized. It was found that $N$-terminal acetylation as well as replacement of the non-natural Nle in place of Leu/Ile retained affinity at the B2R $\left(\mathrm{IC}_{50} \sim 150 \mathrm{nM}\right)$. $C$-Terminal amidation as well as inverso modifications resulted in a complete loss of affinity at the $\mathrm{B} 2 \mathrm{R}\left(\mathrm{IC}_{50}>10,000 \mathrm{nM}\right)$. Although a complete reverse of chirality resulted in loss of affinity, a D amino acid scan found that a single substitution of $\mathrm{DPhe}^{4}, \mathrm{DLeu}^{5}$, or $\mathrm{DArg}^{6}$ resulted in a retention of affinity $\left(\mathrm{IC}_{50} \sim 200 \mathrm{nM}\right.$ ), whereas substitutions with the D-isomer at other positions resulted in a loss of affinity $\left(\mathrm{IC}_{50}=800-10,000 \mathrm{nM}\right)$. 


\section{Stability Assay of Analogues}

To test the stability of the ligands, an in vitro stability assay in rat plasma was carried out. As expected, the lead ligand, LYS1044 was quickly degraded with a $t_{1 / 2}$ $=0.7 \mathrm{hr}$. Ligands that were substituted with D-isomers near the $N$-terminus and retained affinity at the B2R were found to be much more stable than the parent ligand (Figure 2). In particular SH146, was extremely stable $\left(\mathrm{t}_{1 / 2}=160 \mathrm{hr}\right)$ with $99 \%$ of the peptide remaining after $24 \mathrm{hrs}$. This ligand was substituted with DLeu ${ }^{5}$. The importance of modifications at this position was further confirmed when a ligand with substitution of $N$-methylation $\mathrm{Leu}^{5}$ was tested and $99 \%$ of the peptide was intact after a $24 \mathrm{hr}$ incubation. Similar results were also found in human plasma.

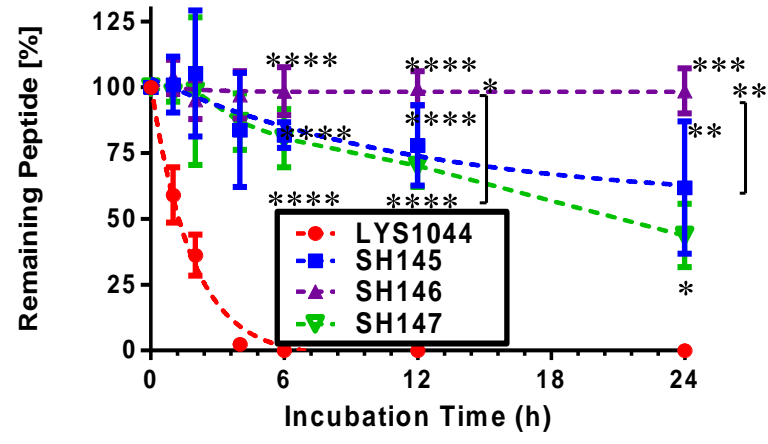

Fig. 2. Stability assay in rat plasma. LYS1044, the lead ligand, had a short $t_{1 / 2}$ whereas substitution with $D$ isomer (SH145-Sh147) lead to large increases in stability.

\section{Conclusions}

We have performed an SAR study and have found a lead ligand for the B2Rs as well as ligands that were modified for stability. A ligand modified at $\mathrm{Leu}^{5}$ was found to be more stable than the parent ligand $\left(\mathrm{t}_{1 / 2}=0.7 \mathrm{hr}\right.$ vs $16 \mathrm{hr}$ ) and was also found to be non-toxic in an in vitro cell assay. Further studies will be carried out to test the ligand's effectiveness as an analgesic.

\section{Acknowledgments}

We thank Andy Ambrose, Robert Kupp, and Lindsay Lebaron for their help in synthesis and bioassay of ligands. Supported by grants from the U.S. Public Health Services, NIH, and NIDA (P01DA006248). We also thank APS and the GPSC at the University of Arizona for their support in attending the conference.

\section{References}

1. Chavkin, C., Goldstein, A. Science 215, 413 (1982), http://dx.doi.org/10.1126/science.6120570

2. Lai, J., Luo, M.C., Chen, Q.M., Ma, S.W., Gardell, L.R., Ossipov, M.H., Porreca, F. Nature Neuroscience 9 , 1534-1540 (2006), http://dx.doi.org/10.1038/nn1804

3. Luo, M.C., Chen, Q.M., Ossipov, M.H., Rankin, D.R., Porreca, F., Lai, J. J. Pain 9, 1096-1105 (2008), http://dx.doi.org/10.1016/j.jpain.2008.06.005

4. Lee, Y.S., Muthu, D., Hall, S.M., et al. J. Am. Chem. Soc. 136, 6608-6616 (2014), http://dx.doi.org/10.1021/ja501677q 